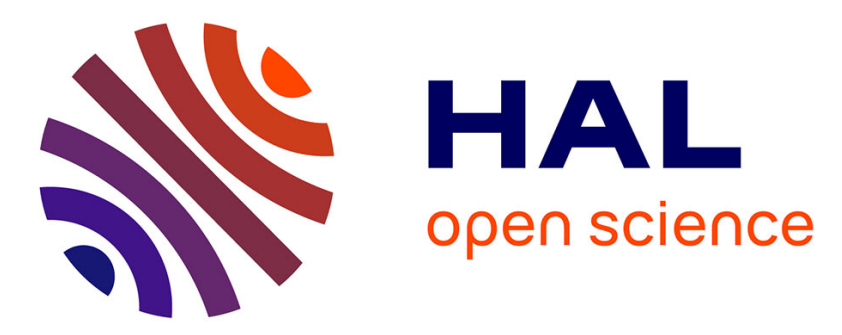

\title{
Impact of thermal oxidation on mechanical behavior of polydicylopentadiene: Case of non-diffusion limited oxidation
}

\author{
Adelina David, Jing Huang, Emmanuel Richaud, Pierre Yves Le Gac
}

\section{- To cite this version:}

Adelina David, Jing Huang, Emmanuel Richaud, Pierre Yves Le Gac. Impact of thermal oxidation on mechanical behavior of polydicylopentadiene: Case of non-diffusion limited oxidation. Polymer Degradation and Stability, 2020, 179, pp.109294. 10.1016/j.polymdegradstab.2020.109294 . hal02937499

\author{
HAL Id: hal-02937499 \\ https://hal.science/hal-02937499
}

Submitted on 14 Sep 2020

HAL is a multi-disciplinary open access archive for the deposit and dissemination of scientific research documents, whether they are published or not. The documents may come from teaching and research institutions in France or abroad, or from public or private research centers.
L'archive ouverte pluridisciplinaire HAL, est destinée au dépôt et à la diffusion de documents scientifiques de niveau recherche, publiés ou non, émanant des établissements d'enseignement et de recherche français ou étrangers, des laboratoires publics ou privés. 


\title{
Impact of thermal oxidation on mechanical behavior of polydicylopentadiene: Case of non-diffusion limited oxidation
}

\author{
Adelina David ${ }^{a}$, Jing Huang ${ }^{b}$, Emmanuel Richaud ${ }^{b}$, Pierre Yves Le Gac ${ }^{\text {a, * }}$ \\ a IFREMER, Service Matériaux et Structures, Centre de Brest BP70, F-29280, Plouzané, France \\ b Laboratoire PIMM, Arts et Métiers, CNRS, Cnam, HESAM Université, 151 Boulevard de L'Hôpital, F-75013, Paris, France
}

Keywords:

Polydicyclopentediene

Thermal oxidation

Mechanical properties

Fracture properties

\begin{abstract}
A B S T R A C T
Impact of thermal oxidation on mechanical behavior of polydicyclopentadiene (pDCPD) is studied in this paper. Thermal oxidation is performed over a wide range of ageing temperature, from $20{ }^{\circ} \mathrm{C}$ to $120{ }^{\circ} \mathrm{C}$ using $60 \mu \mathrm{m}$ thin films in order to avoid heterogeneous degradation through sample thickness. After several ageing durations, chemical changes were monitored using Fourier-transform infrared spectroscopy (FTIR) and network modification (e.g. glass transition, Tg) was measured using dynamic mechanical analysis (DMA). In addition, tensile tests and fracture tests, based on the essential work of fracture (EWF) concept, were used to study how oxidation affects some mechanical properties of pDCPD. During oxidation polydicyclopentadiene undergoes crosslinking due to the presence of double bonds that leads to a large increase in $\mathrm{T}_{\mathrm{g}}$ (from 150 to $225^{\circ} \mathrm{C}$ ) as well as an increase in rubbery modulus. This increase in $\mathrm{T}_{\mathrm{g}}$ results in an increase in maximal stress that can be described using the Kambour relationship. In parallel, an embrittlement of the polymer is observed here with a decrease in both essential and non-essential work of fracture. Finally, it appears that the accelerating effect of ageing temperature can be described using an Arrhenius equation with an activation energy close to $65 \mathrm{~kJ} / \mathrm{mol}$ for carbonyl formation, maximal stress changes and decrease in fracture energy.
\end{abstract}

\section{Introduction}

Polydicyclopentadiene is a relatively young polymer compared to other polyolefins such as polypropylene or polyethylene. This 'new' material exhibits some very interesting properties such as high $T_{g}$, very low cycle time (within a few minutes for $10 \mathrm{~cm}$ thick coating [1,2]) and good fatigue resistance [3]. Thanks to such specific properties pDCDP is used for very demanding applications. This material has been studied recently for offshore oil and gas application [1-3]. One of the main conclusions in Refs. [1] was that this polymer is very interesting for high temperature applications in sea water but has one important drawback; its sensitivity to oxidation. Since then, many papers have considered pDCPD oxidation in terms of chemical mechanisms and kinetic modelling. Nevertheless, very few data are available about the mechanical consequences of this oxidation; this is the aim of this study.

First, it is worth noting that oxidation in pDCDP is very fast compared to common polymers such as polypropylene [4].,

\footnotetext{
* Corresponding author.

E-mail address: pierre.yves.le.gac@ifremer.fr (P. Yves Le Gac).
}

polyethylene [5]. and rubbers [6]. This behavior is attributed to a very slow termination process $[7,8]$. It should be mentioned that this high oxidation rate can be largely reduced using stabilizers for industrial applications [9]. Second, pDCDP has a large number of double bonds within its backbone (up to $13 \mathrm{~mol} / \mathrm{L}$ see Ref. [10]) that affect oxidation mechanisms. In fact, in the presence of double bonds, radicals react directly with these double bonds during the propagation step [10]. This reaction leads to the formation of a new chemical bond and so an increase in the crosslink density of the polymer. Finally, based on literature, it appears that oxidation leads to large changes in mechanical behavior $[1,11]$. However, all these tests were performed on thick samples, i.e. with an oxidation profile through the sample thickness. In fact, when considering polymer oxidation two cases are possible. Either oxygen diffusion is faster than oxygen consumption by oxidation, meaning that oxidation is homogeneous through the sample thickness. Or oxidation is limited by oxygen diffusion (because oxygen consumption is faster) and so an oxidation gradient occurs in the sample. In this second case, interpretation of mechanical data is very complex. In the present study thin films are used in order to avoid any heterogeneity through sample thickness. 
In this paper we will first describe the material under study and the methods used here. Then, results will be presented, considering first changes at the molecular scale, followed by the macromolecular scale, and finally mechanical properties. Two kinds of mechanical tests will be considered; the classical tensile test and also a crack propagation measurement, in order to have a better characterization of fracture properties. Finally the results will be discussed in order to extract an end of life criterion in order to predict life time of this polymer in service conditions.

\section{Material and methods}

\subsection{Material}

The poly (dicyclopentadiene) samples under investigation (Telene 18xx, Telene SAS) were supplied as a stabilized plate material prepared by the reaction injection molding process (RIM). Raw material was injected at $25{ }^{\circ} \mathrm{C}$ in a glass mould. The catalyst used for the metathesis polymerization is a ruthenium salicylaldimine phenylindenylidene complex. Details about curing conditions are available in Ref. [10]. Samples were stabilized with $0.0226 \mathrm{~mol} \mathrm{l}^{-1}$ butylated hydroxytoluene. By cutting the plate material with a microtome, films having a thickness between 60 and $20 \mu \mathrm{m}$ were obtained. It is important to note that this thickness is low enough to avoid the Diffusion-Limited Oxidation (DLO) effects, see results section. Samples were stored at $-20{ }^{\circ} \mathrm{C}$ before ageing for a maximum of a week.

\subsection{Exposure conditions}

Samples were exposed in ventilated ovens at various temperatures ranging from 120 to $20^{\circ} \mathrm{C}$. Exposures at $20^{\circ} \mathrm{C}$ were performed in an air-conditioned laboratory where the oxidizing source is atmospheric oxygen.

\subsection{Fourier transform infrared spectroscopy}

FTIR spectra were obtained by averaging 32 scans at a $4 \mathrm{~cm}^{-1}$ resolution over a spectral range from 600 to $4000 \mathrm{~cm}^{-1}$ using a Frontier apparatus (PerkinElmer) in transmission mode. Spectra were then analysed with Spectrum ${ }^{\mathrm{TM}}$ software. The concentration of carbonyls measured at $1715 \mathrm{~cm}^{-1}$ is normalized using absorbance at $2852 \mathrm{~cm}^{-1}$ ascribed to $\mathrm{C}-\mathrm{H}$ stretching.

\subsection{Dynamic mechanical analysis}

Dynamic mechanical analysis was performed on a 2980 device from TA Instruments. Measurements were performed in tensile mode at $1 \mathrm{~Hz}$ with an auto-tension of $125 \%$ and a static force of $0.2 \mathrm{~N}$ on $12 \mathrm{~mm} \times 5 \mathrm{~mm} \times 0.06 \mathrm{~mm}$ samples. Heating rate was $3^{\circ} \mathrm{C} /$ min between $60{ }^{\circ} \mathrm{C}$ and $300{ }^{\circ} \mathrm{C}$. Tests were performed under $\mathrm{N}_{2}$ to limit the oxidation effect and samples were ageing directly in the DMA oven. The glass transition temperature was defined as the centre of the E' drop.

\subsection{Tensile tests}

Tensile tests were performed using $60 \mu \mathrm{m}$ thick samples in order to obtain homogeneous oxidation through the sample thickness. Samples were cut in a dog-bone shape with an initial working length of $10 \mathrm{~mm}$. They were tested after several ageing durations using an Instron test machine with a $50 \mathrm{~N}$ load cell. Tests were performed at $2 \mathrm{~mm} / \mathrm{min}$ and strain measured by Digital Image Correlation. For each condition, at least 8 samples were characterized in order to ensure reliability of results.

\subsection{Essential work of fracture measurement}

Essential Work of Fracture (EWF) measurements were performed on an Instron ${ }^{\mathrm{TM}}$ test machine with a $50 \mathrm{~N}$ load cell, in double notched tensile mode, with a loading rate of $2 \mathrm{~mm} / \mathrm{min}$. Samples were $60 \mu \mathrm{m}$ thick with a width of $10 \mathrm{~mm}$. They were notched on each side using a scalpel, the distance between the two notches (ligament length, L) was in the range between 3 and $9 \mathrm{~mm}$. Tests were recorded with a high resolution camera (Camera Basler ${ }^{\mathrm{TM}}$ PIA 2400-12 GM). Images from the camera were used to measure the actual ligament length (L) before testing and fracture energy was measured from the area of the load/displacement curve. For each condition, at least 8 samples were characterized in order to ensure reliability of results. More details about concept and methodology are available in Refs. [12-14]. The fracture energy $\left(\mathrm{W}_{\mathrm{f}}\right)$ is measured from the area of the load/displacement curve, see Fig. 9 and then plotted as a function of ligament length, see Fig. 10. From these curves we can define $W_{\mathrm{e}}$ which is the essential work of fracture and determined as the intercept of the curve $W_{f}=f(L)$. $\beta W_{p}$ which is the slope of the curve $W_{f}=f(L)$ is also obtained and is usually called the non essential work of fracture.

\section{Results}

\subsection{Changes at the molecular scale}

Results from FITR measurement for several ageing durations in an oven at $60{ }^{\circ} \mathrm{C}$ are presented in Fig. 1. As expected during the degradation of the material we can observe an increase of two characteristic bands at $3400 \mathrm{~cm}^{-1}$ and $1750 \mathrm{~cm}^{-1}$. These two bands are attributed to oxidation products, respectively hydroxyl and carbonyl groups, the general oxidation scheme of pDCPD is available in Ref. [15] At the same time, a decrease of the band situated at $1650 \mathrm{~cm}^{-1}$ and attributed to the double bond in the polymer is observed, see Ref. [10] for details. All these observations are in accordance with existing knowledge on oxidation of pDCPD [1-13,16]. FTIR results obtained at several ageing temperatures are plotted in Fig. 2. For all ageing temperatures considered here, we observe first an induction period where oxidation products are not formed and then an acceleration of the oxidation rate. It is worth noting, that thanks to the fact that oxidation is fast in PDCPD it is possible to consider oxidation rates over a large range of temperature, even at room temperature. For the 7 temperatures considered here, the same behavior is observed: first an induction period where almost no carbonyl groups are formed and then a large

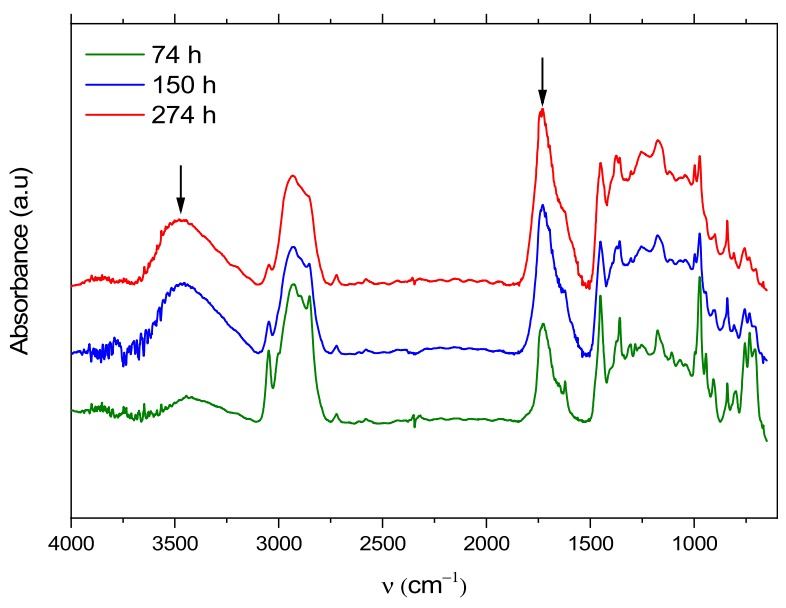

Fig. 1. Changes in FTIR spectrum as function of ageing time at $60{ }^{\circ} \mathrm{C}$. 


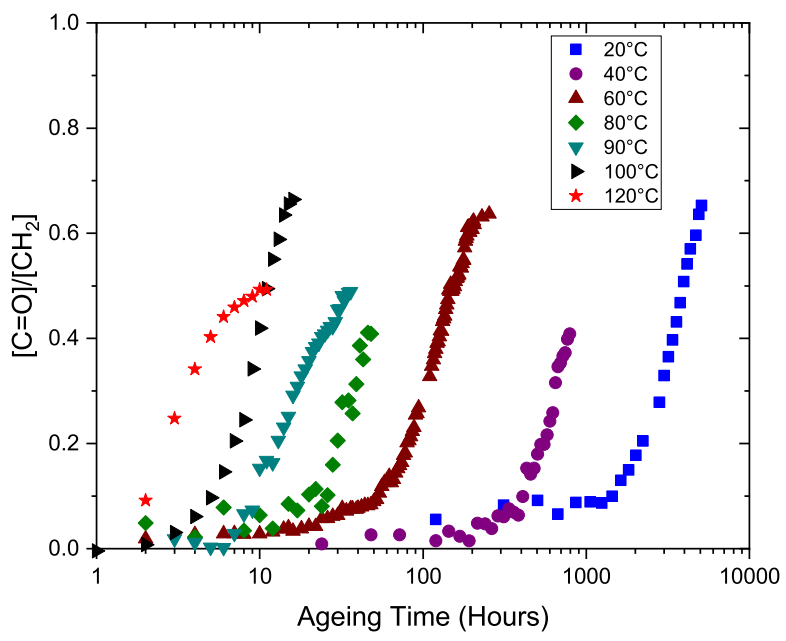

Fig. 2. Oxidation products build up as function of ageing time for temperatures from 120 to $20^{\circ} \mathrm{C}$.

increase in carbonyl content related to the auto-acceleration of oxidation. Due to the fact that oxidation is fast in PDCPD it is possible to consider oxidation rates over a large range of temperatures, and even at room temperature. These data will be useful to evaluate whether oxidation at the molecular scale in pDCDP can be analysed using an Arrhenius approach (see discussion). Using these data coupled with oxygen properties in pDCPD from Ref. [8], it is possible to calculate the oxidized thickness according to:

$\mathrm{TOL}=\sqrt{\frac{D_{o 2}}{V_{o x} /\left[O_{2}\right]}}$

Where TOL is the thickness of oxidized layer, $\mathrm{D}_{\mathrm{O} 2}$ the oxygen diffusivity and equal to $8.10^{-8} \mathrm{~cm}^{2} \mathrm{~s}^{-1}$ at $25^{\circ} \mathrm{C}$ with an activation energy of $15 \mathrm{~kJ} \mathrm{~mol}^{-1},\left[\mathrm{O}_{2}\right]$ the oxygen concentration (calculated with a solubility of $10^{-7} \mathrm{~mol} \mathrm{~L}^{-1} \mathrm{~Pa}^{-1}$ ) and Vox the value of oxidation rate from FTIR [10].

Results are given in Table 1 and clearly show that within the temperature range considered here, $60 \mu \mathrm{m}$ thick samples are homogeneously oxidized (because sample thickness is less than $2 * \mathrm{TOL})$.

\subsection{Change at the network scale - DMA}

The impact of oxidation on pDCDP will now be considered at the macromolecular scale using DMA characterization. Samples were aged in an oven at $60^{\circ} \mathrm{C}$ and then characterized by DMA from this temperature to $300{ }^{\circ} \mathrm{C}$ in an inert atmosphere. The raw data obtained are plotted in Fig. 3. It appears, from Fig. 3, that both $\mathrm{T}_{\mathrm{g}}$ and storage modulus in the rubbery state increase during ageing. An increase of the modulus in the glassy state can be observed that could be related to an increase in cohesion within the polymer due to the presence of polar groups generated by oxidation. In fact, it has been shown in the past that modulus increases when the density of cohesion energy density increases in the polymer [17].

The increase in both $\mathrm{T}_{\mathrm{g}}$ and rubbery modulus is clear evidence of an increase in crosslink density of the material. This crosslinking

Table 1

Calculation of the oxidized layer as a function of ageing temperature.

\begin{tabular}{llllllll}
\hline Temperature & $20{ }^{\circ} \mathrm{C}$ & $40{ }^{\circ} \mathrm{C}$ & $60{ }^{\circ} \mathrm{C}$ & $80{ }^{\circ} \mathrm{C}$ & $90{ }^{\circ} \mathrm{C}$ & $100{ }^{\circ} \mathrm{C}$ & $120^{\circ} \mathrm{C}$ \\
\hline $2 *$ TOL $(\mu \mathrm{m})$ & 880 & 457 & 257 & 154 & 122 & 98 & 65 \\
\hline
\end{tabular}

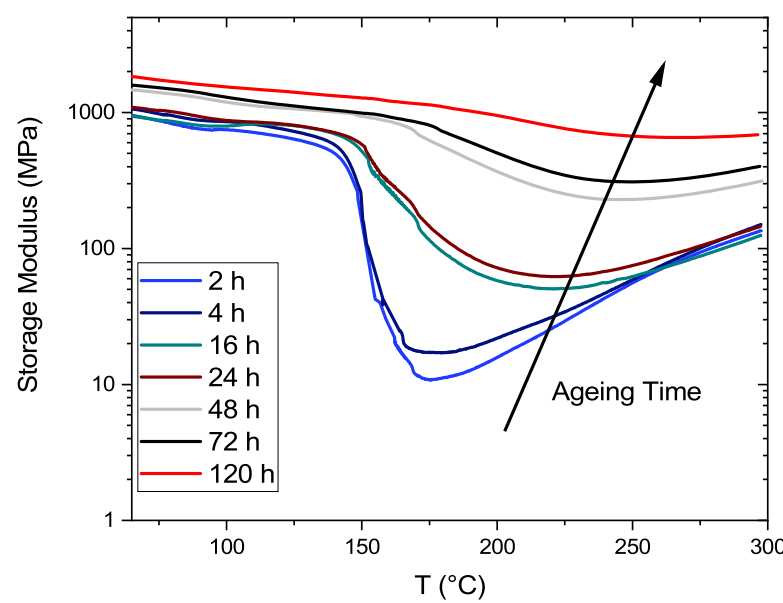

Fig. 3. Changes in DMA results as a function of ageing time at $60^{\circ} \mathrm{C}$.

process during pDCDP oxidation has already been highlighted in the literature [10] and can be attributed to the reaction of radicals on the double bonds available in large quantity in this polymer; this process has been studied in detail with other polymers [18-20]. In fact, when radicals react with the double bond a new bond is created leading to an increase in crosslink density. This increase in crosslink density is also confirmed by the large increase in rubbery modulus. Fig. 4 shows an increase in $\mathrm{T}_{\mathrm{g}}$ as a function of oxidation level with a value of $150{ }^{\circ} \mathrm{C}$ for unaged material that reaches $220^{\circ} \mathrm{C}$ after oxidation. It clearly appears that the $\mathrm{T}_{\mathrm{g}}$ of $\mathrm{pDCPD}$ increases with oxidation level. This point confirms the crosslinking process that occurs during oxidation of pDCPD.

\subsection{Change in mechanical properties}

\subsubsection{Tensile behavior}

Thin films were aged in an oven for several durations and then tensile tests were performed. Results obtained after oxidation at $80{ }^{\circ} \mathrm{C}$ are presented in Fig. 5. First, these results highlight the fact that, without DLO, mechanical properties of pDCDP are very sensitive to oxidation. In fact, a large decrease in elongation at break is observed for very short ageing times, i.e. less than $1 \mathrm{~h}$. For longer ageing duration (i.e. between 1 and $64 \mathrm{~h}$ ), the strain at break decreases very slowly, and an increase in maximal stress is observed

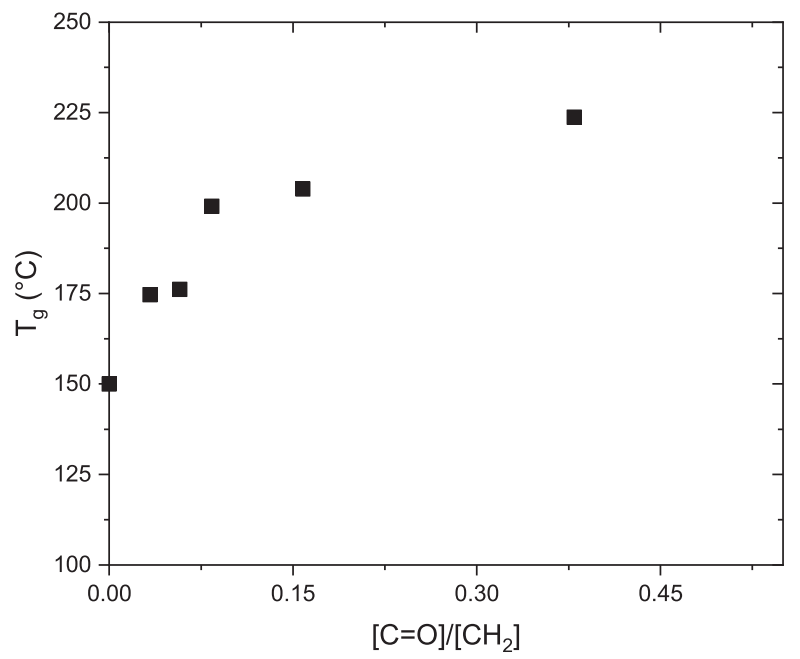

Fig. 4. Increase in $\mathrm{T}_{\mathrm{g}}$ as a function of carbonyl concentration in pDCPD at $60{ }^{\circ} \mathrm{C}$. 


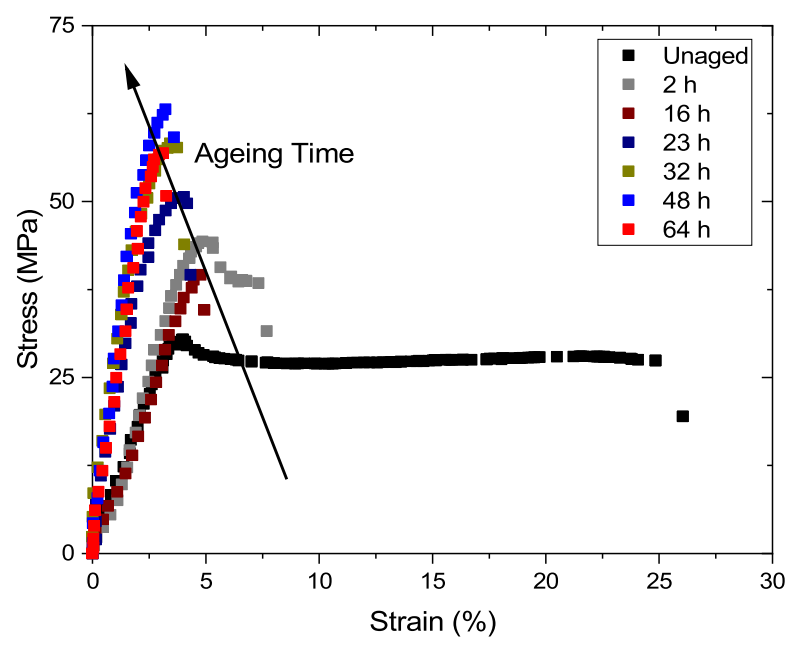

Fig. 5. Changes in tensile stress-strain plots during thermal oxidation of pDCPD at $80^{\circ} \mathrm{C}$.

(this point will be discussed later). Finally, the material becomes so brittle that it can no longer be tested. At the same time, an increase in glassy modulus (from $0.8 \mathrm{GPa}$ for unaged material to $2 \mathrm{GPa}$ for samples aged for $64 \mathrm{~h}$ at $80^{\circ} \mathrm{C}$ ) is observed suggesting an increase of the cohesion in the polymer with oxidation.

When considering oxidation of polymers, high temperature is usually needed to accelerate ageing and obtain information about durability in service within a reasonable duration. Here, because oxidation is fast, it is possible to compare results obtained at high ageing temperature (up to $120{ }^{\circ} \mathrm{C}$ ) to those obtained at service temperature (here $20^{\circ} \mathrm{C}$ ); extrapolation in terms of kinetic rate will be discussed later. For all ageing temperatures (from $120{ }^{\circ} \mathrm{C}$ to $20{ }^{\circ} \mathrm{C}$ ), the observed behaviour is as follows (see Fig. 7):

i) an increase in maximal stress from about $35 \mathrm{MPa}$ to $60 \mathrm{MPa}$ and then a drop off when the material becomes brittle. This behavior is due to the fact that, in glassy polymers, the maximal stress is directly proportional to the difference between testing temperature and the $T_{g}$ of the polymer. This kind of relationship was first described by Kambour [21] and can be written as follows:

$\sigma_{\max }=\mathrm{A} *\left(\mathrm{~T}_{\mathrm{g}}-\mathrm{T}\right)+\mathrm{B}$

Where $\sigma_{\max }$ is the maximal stress (in MPa), Tg the glass temperature of the polymer (in ${ }^{\circ} \mathrm{C}$ ), $\mathrm{T}$ the testing temperature (in ${ }^{\circ} \mathrm{C}$ ) and $\mathrm{A}$ and $\mathrm{B}$ are material properties.

Here, because of the crosslinking process, an increase in $T_{g}$ occurs (see Fig. 4) whereas testing temperature remains the same. The unexpected increase in maximal stress is thus explained by this large increase in $\mathrm{T}_{\mathrm{g}}$, see Fig. 6 . When the material becomes brittle, a decrease in maximal stress is then observed because failure occurs before plastic deformation of the material. It is worth noting that the factor $\mathrm{A}$ is close to 0.25 for $\mathrm{pDCPD}$; that is a low value compared to epoxy [22] or polyamide [23].

\subsubsection{Crack propagation}

Tensile tests clearly show an embrittlement of the material during oxidation with a large decrease in strain at break. However, in terms of mechanics, strain at break values can be questionable especially when considering thin films such as those tested here because defects on sample edge are not always avoided during sample preparation. In order to overcome this limitation of tensile

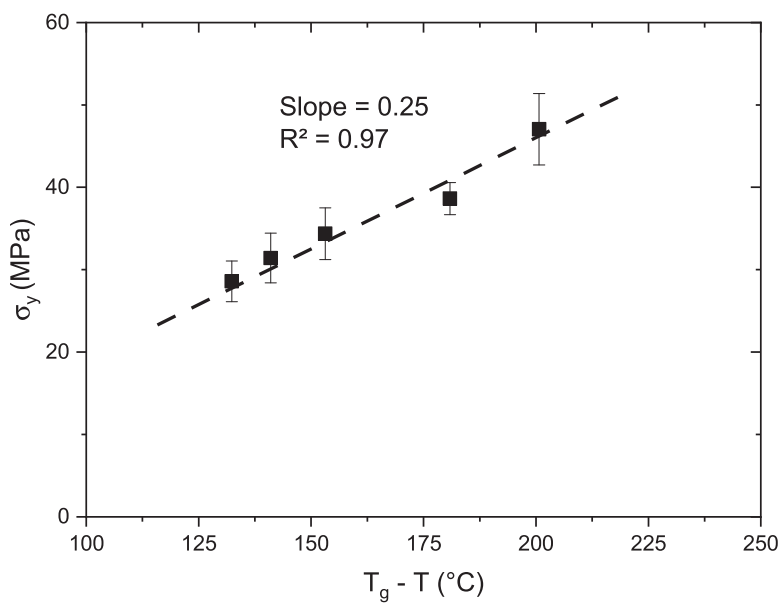

Fig. 6. Plot of maximal stress as function of Tg-T in pDCPD with data obtained at $60^{\circ} \mathrm{C}$

ii) Considering strain at break, a decrease appears for all ageing temperatures, see Fig. 7. This means that, at least for pDCDP without DLO, changes in tensile behavior obtained after accelerated ageing are relevant for prediction at service temperature. In order to study in more detail the observed embrittlement of pDCPD with ageing, a crack propagation characterization has been performed and results will be presented in the next section. At $60^{\circ} \mathrm{C}$, after $120 \mathrm{~h}$ of ageing, the oxidation level reaches a plateau (see Fig. 1), the $\mathrm{T}_{\mathrm{g}}$ is equal to $225{ }^{\circ} \mathrm{C}$ (see Fig. 3 ) and the material becomes brittle with a drop in maximal stress and strain at beak (Fig. 7)

tests and to access more information about the polymer fracture, crack propagation tests were performed. In this case cracks are created in the sample prior to testing and then the energy needed to propagate these cracks is measured. During testing the measured energy is not only related to the propagation of this crack, in fact around the crack there is a large deformation of the polymer due to the mechanical stress field. In other words, crack propagation energy depends on the ligament length as shown in Fig. 8 for unaged pDCDP. Using these data with several ligament lengths it is possible to distinguish the non-essential work that is related to deformation around the crack and the essential work of fracture that is directly related to the crack propagation, and thus a material property. More details about the EWF concept can be found in Refs. [12-14]. Results obtained during oxidation at $60^{\circ} \mathrm{C}$ are plotted in Fig. 8 .

In Fig. 9 it appears that, for unaged material, the energy needed to propagate the crack depends strongly on the ligament length meaning that the material is not brittle. This is in accordance with tensile results. As long as oxidation occurs, the $\beta W_{p}$ value, i.e. the slope of the curve presented in Fig. 10, decreases. When the slope is equal to 0 (for 2 days in Fig. 9) it means that the polymer is brittle. For higher oxidation levels, a decrease in $\mathrm{W}_{\mathrm{e}}$ (i.e. intercept: energy for a ligament length equal to 0 ) is observed when degradation progresses. The same behavior has been observed for all tested temperatures $\left(90,60\right.$ and $\left.40^{\circ} \mathrm{C}\right)$. The decrease in fracture properties is discussed in the next section together with accelerating factors and the relationship with oxidation products concentration.

\section{Discussion}

In this section the lifetime prediction of pDCPD will be discussed, based on the results presented above. First, the long-term prediction of mechanical behavior of pDCDP will be addressed using a simple empirical Arrhenius extrapolation. Then the relationship between mechanical properties and oxidation level in pDCPD will be examined. 

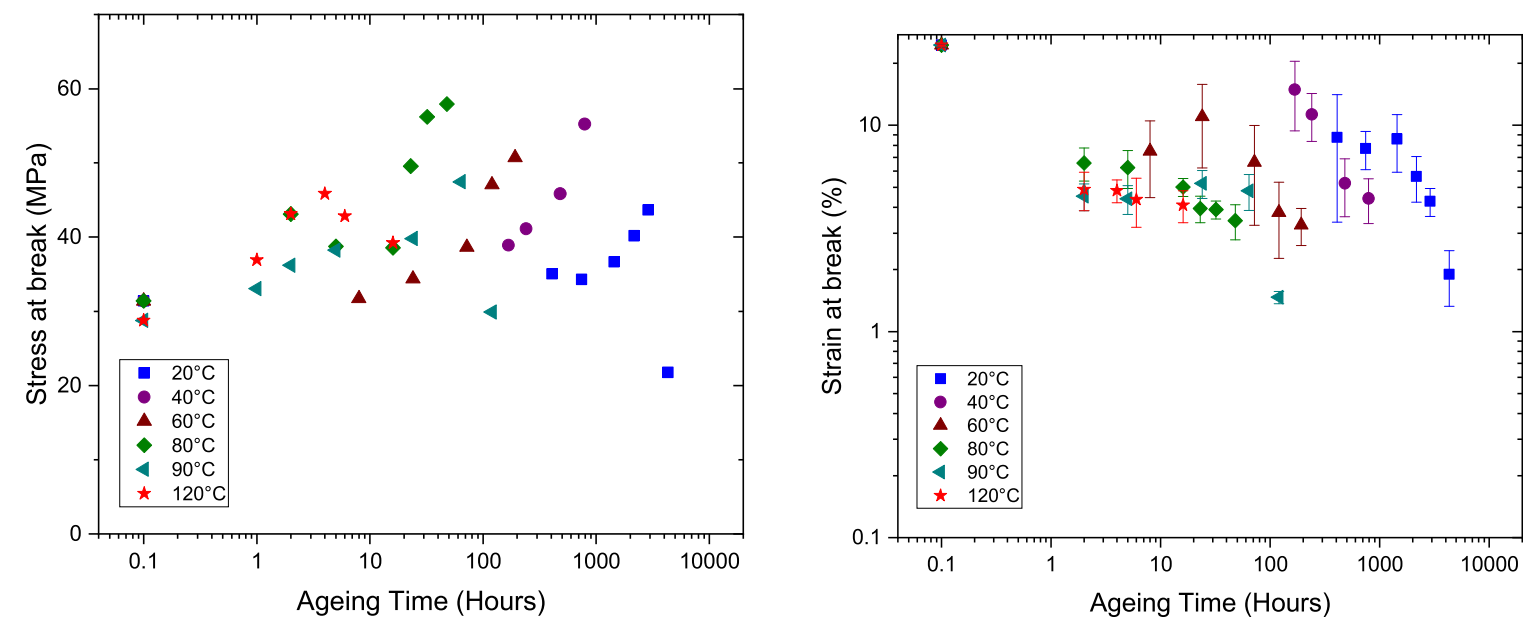

Fig. 7. Impact of ageing temperature on maximal stress (left) and strain at break (right) changes during oxidation.

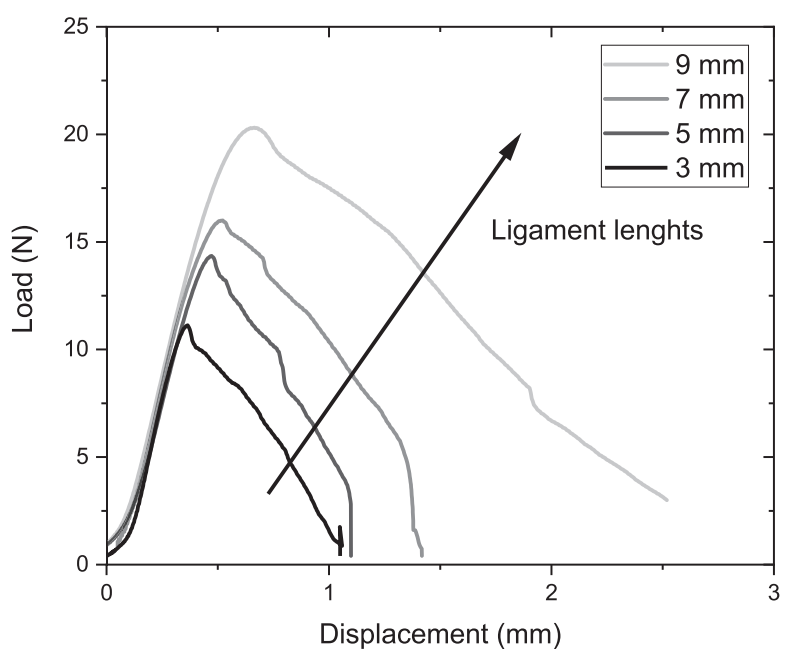

Fig. 8. Typical crack propagation curves with unaged pDCDP for 4 different ligament lengths from 3 to $9 \mathrm{~mm}$.

\subsection{Prediction using Arrhenian behavior}

Here we focus on the question; can we describe mechanical property loss during oxidation using a simple Arrhenius equation? Arrhenius plots are presented in Fig. 10 for oxidation rate based on (a) FTIR, (b) shift factor to describe change in maximal stress and (c) the essential work of fracture. For the three characteristics considered here the temperature dependence can be described using an Arrhenius equation with an activation energy close to $65 \mathrm{~kJ} \mathrm{~mol}^{-1}$. This activation energy is much lower than for PP or PE $[4,5]$, this difference can be explained by the low activation energy of the initiation step in pDCPD [10]. It clearly appears that oxidation rate and mechanical property changes due to oxidation in pDCPD can be described using a simple empirical equation. It is worth noting that the induction times also follow an Arrhenius equation with a very similar activation energy. However, it is necessary to recall that such predictions can be made using Arrhenius extrapolation here only because:

- oxidation is not limited by oxygen diffusion [24-26]. In fact, when oxidation rate is faster than the oxygen diffusion supply, then oxidation levels are heterogenous through the sample thickness. In this case the mechanical behavior does not generally follow an Arrhenius behaviour because at least two processes are involved, each with its own activation energy.

- changes in chemistry or mechanical behaviour due to oxidation are studied, here, over a wide range of temperature that allows an accurate determination of the activation energy. In fact, when activation energy is determined with only a few ageing temperatures or in a limited range of temperatures reduced accuracy in the activation energy value is likely, leading to an inaccurate prediction at service temperature [27].

To conclude this section, it appears that for pDCDP, when no DLO
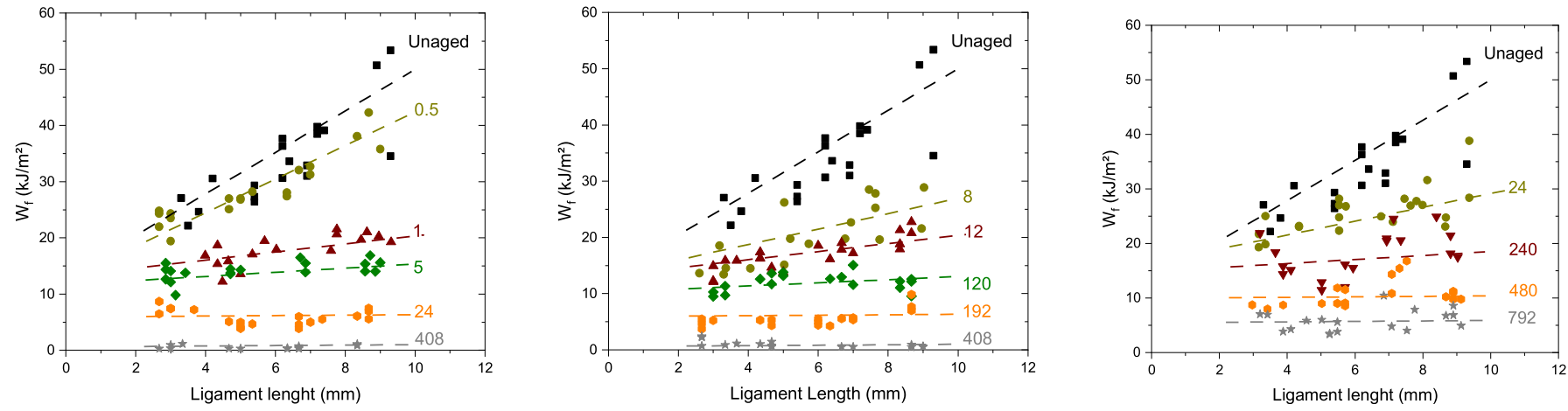

Fig. 9. Fracture energy $\left(\mathrm{W}_{\mathrm{f}}\right)$ as a function of ligament length for several ageing durations at $90{ }^{\circ} \mathrm{C}$ (a) $60{ }^{\circ} \mathrm{C}$ (b) and $40{ }^{\circ} \mathrm{C}$ (c). The number indicates ageing time in hours. 

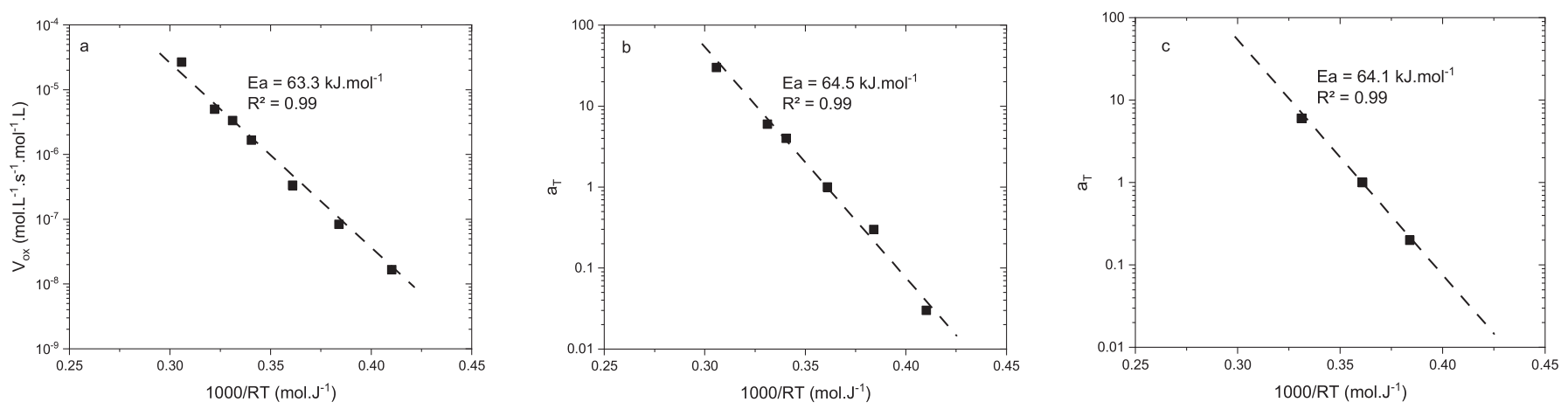

Fig. 10. Arrhenius plot of Oxidation rate (a), shift factor considering maximal stress (b) and $W_{e}(c)$ as a function of $1000 / R T$.

occurs and with a wide range of ageing temperatures, it is possible to use an Arrhenius equation to describe the accelerating factor generated by increasing ageing temperature. However, it should be noted that if there is any change in formulation (type or concentration of stabilizers) it is necessary to check again whether Arrhenius can be used to obtain a reliable extrapolation. In order to overcome this limitation, kinetic modeling can be applied [10]. Modeling of pDCDP exists but it only allows changes to be predicted at the molecular scale. It is thus necessary to propose a relationship between the mechanical properties of interest and changes at the molecular scale; this is the aim of the next section.

\subsection{Relationship between fracture properties and oxidation products}

The question here is, can we directly link mechanical behaviour changes of pDCPD with the formation of oxidation products (carbonyl groups) independently of the ageing temperature or oxidation rate? This kind of empirical relationship can be very useful in order to perform prediction of the mechanical behavior based on kinetic modelling that only considers oxidation at the molecular scale. We focus here on fracture properties of pDCPD for two main reasons. First it appears that this property is much more sensitive than tensile behavior to embrittlement during ageing. Second, pDCPD is not used in thin films but with large thickness (i.e. from few $\mathrm{mm}$ to several $\mathrm{cm}$ ); in this case oxidation is limited to the surface, and will generate the first crack depending on the fracture properties of this layer. Fracture properties presented in Fig. 11 are calculated from EWF results for a $5 \mathrm{~mm}$ ligament length as an

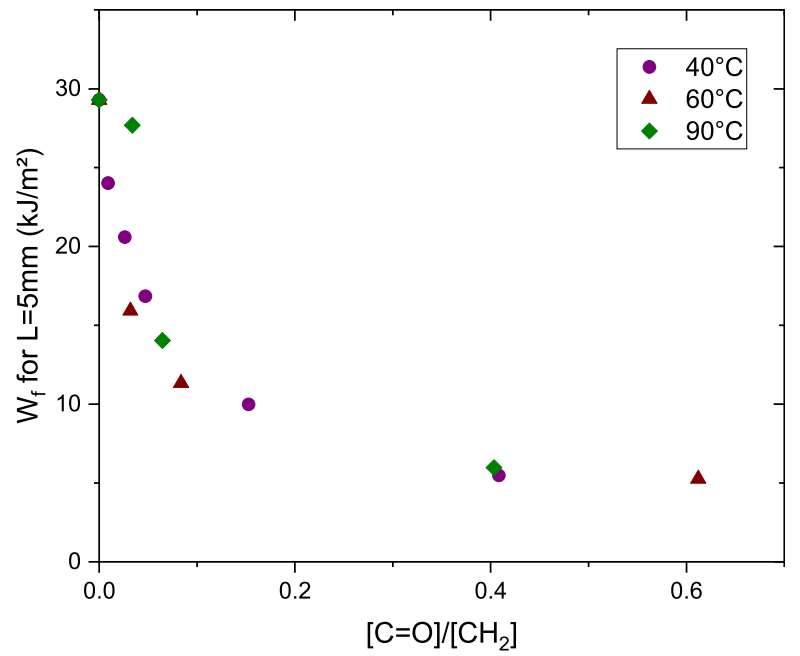

Fig. 11. Fracture energy for a $5 \mathrm{~mm}$ length calculated using We and $\beta \mathrm{Wp}$ determined by EWF as a function of carbonyl content for 3 ageing temperatures. example and plotted as a function of carbonyl concentration. From this plot it appears that the same behavior is observed for the 3 ageing temperatures considered here and it is possible to propose an empirical relationship between fracture properties of pDCPD and the oxidation level. The most interesting point is probably the definition of a critical concentration in oxidation product. In fact, based on these results it is possible to define a maximum admissible carbonyl concentration depending on the application, and more specifically on the required polymer fracture resistance.

\section{Conclusions}

The influence of oxidation on mechanical properties of a stabilized pDCPD has been considered over a wide range of ageing temperatures, from 120 to $20^{\circ} \mathrm{C}$. For all ageing conditions considered here oxidation is homogenous through the sample thickness, in order to have a better understanding of the effect on the mechanical behaviour of pDCDP.

During oxidation extensive crosslinking occurs in pDCDP mainly due to the reaction of radicals on the double bonds during the propagation step. This increase in crosslink density leads to a decrease in macromolecule mobility and a large increase in $\mathrm{T}_{\mathrm{g}}$ (from $150{ }^{\circ} \mathrm{C}$ to $225{ }^{\circ} \mathrm{C}$ at $60{ }^{\circ} \mathrm{C}$ ). Tensile behavior of the material is strongly affected by oxidation, with a decrease in elongation at break. Considering maximal stress, an increase is observed first, and then a reduction occurs. The increase in maximal stress can be related to the increase in $T_{g}$ through the Kambour relationship. Fracture properties of pDCDP and their modification with oxidation level have been considered using the Essential Work of Fracture concept here for the first time. A fast decrease in $\beta \mathrm{Wp}$ is observed, that is related to the ability of the polymer to undergo plastic deformation. And then a decrease in We occurs when the ability of macromolecules to be stretched decreases.

Considering all the results of this study it appears that oxidation in pDCDP obeys an Arrhenian behavior over the entire temperature range considered here, with an activation energy close to $65 \mathrm{~kJ} / \mathrm{mol}$ However, it is important to keep in mind that this result may depend on pDCPD formulation and thickness. In order to overcome this limitation, an empirical relationship between the level of oxidation and fracture properties has been proposed, whatever the ageing temperature. This kind of relationship is needed in order to propose predictive tools for mechanical properties in thick materials based on kinetic models [10].

\section{Declaration of competing interest}

The authors declare that they have no known competing financial interests or personal relationships that could have appeared to influence the work reported in this paper. 


\section{Acknowledgements}

Agence Nationale de la Recherche is gratefully acknowledged for having funded this study (Project VRPOM - Vieillissement des Réseaux Polymérisés par Métathèse - 2016-2019).

\section{References}

[1] P.Y. Le Gac, D. Choqueuse, M. Paris, G. Recher, C. Zimmer, D. Melot, Durability of polydicyclopentadiene under high temperature, high pressure and seawater (offshore oil production conditions), Polym. Degrad. Stabil. 98 (3) (2013) 809-817.

[2] Y. Hu, X. Li, A.W. Lang, Y. Zhang, S.R. Nutt, Water immersion aging of polydicyclopentadiene resin and glass fiber composites, Polym. Degrad. Stabil. 124 (2016) 35-42.

[3] Y. Hu, A.W. Lang, X. Li, S.R. Nutt, Hygrothermal aging effects on fatigue of glass fiber/polydicyclopentadiene composites, Polym. Degrad. Stabil. 110 (2014) $464-472$

[4] L. Achimsky, L. Audouin, J. Verdu, J. Rychly, L. Matisova-Rychla, On a transition at $80 \mathrm{C}$ in polypropylene oxidation kinetics, Polym. Degrad. Stabil. 58 (3) (1997) 283-289.

[5] X. Colin, B. Fayolle, L. Audouin, J. Verdu, About a quasi-universal character of unstabilised polyethylene thermal oxidation kinetics, Polym. Degrad. Stabil. 80 (1) (2003) 67-74.

[6] P.Y. Le Gac, G. Roux, J. Verdu, P. Davies, B. Fayolle, Oxidation of unvulcanized unstabilized polychloroprene: a kinetic study, Polym. Degrad. Stabil. 109 (2014) 175-183.

[7] E. Richaud, P.Y. Le Gac, J. Verdu, Thermooxidative aging of polydicyclopentadiene in glassy state, Polym. Degrad. Stabil. 102 (2014) 95-104.

[8] V. Defauchy, P.Y. Le Gac, A. Guinault, J. Verdu, G. Recher, R. Drozdzak, E. Richaud, Kinetic analysis of polydicyclopentadiene oxidation, Polym. Degrad. Stabil. 142 (2017) 169-177.

[9] Huang J., Le Gac P.Y., Richaud E., Thermal oxidation of poly (dicyclopentadiene)-Effect of phenolic and hindered amine stabilizers. Polymer Degradation and Stability. (2020), 109267.

[10] J. Huang, A. David, P.Y. Le Gac, C. Lorthioir, C. Coelho, E. Richaud, Therma oxidation of Poly (dicyclopentadiene)-kinetic modeling of double bond consumption, Polym. Degrad. Stabil. 166 (2019) 258-271.
[11] Y. Hu, Y. Zhang, S. Nutt, Thermal oxidation aging of polydicyclopentadiene and composites, Polym. Compos. 39 (5) (2018) 1742-1751.

[12] J. Wu, Y.W. Mai, The essential fracture work concept for toughness measurement of ductile polymers, Polym. Eng. Sci. 36 (18) (1996) 2275-2288.

[13] A.B. Martínez, N. León, D. Arencón, M. Sánchez-Soto, Essential work of fracture, crack tip opening displacement, and J-integral relationship for a ductile polymer film, Polym. Test. 55 (2016) 247-256.

[14] B. Fayolle, L. Audouin, J. Verdu, Initial steps and embrittlement in the thermal oxidation of stabilised polypropylene films, Polym. Degrad. Stabil. 75 (1) (2002) 123-129.

[15] J. Huang, Thermal ageing of polydicyclopentadiene (Doctoral dissertation, Ecole nationale supérieure d'arts et métiers, ENSAM, 2019. DOI 2019ENAM0050.

[16] A.A. Lyapkov, E.L. Gvozdkov, A.N. Tarakanovskaya, O.D. Tarnovskaya, Y.S. Yakovleva, Oxidation and Structuring of Polydicyclopentadiene Thin Layers, 2014.

[17] E.M. Bevilacqua, in: LundbergWO (Ed.), Autooxidationandantioxidants, vol. 2, Interscience Publication, New York, 1966, p. 857e918 [(chapter 18)].

[18] F.R. Mayo, Ind. Eng. Chem. 52 (1960) 614.

[19] J.R. Shelton, Rubber Chem. Technol. 45 (12) (1972) 359.

[20] P.Y. Le Gac, M. Celina, G. Roux, J. Verdu, P. Davies, B. Fayolle, Predictive ageing of elastomers: oxidation driven modulus changes for polychloroprene, Polym. Degrad. Stabil. 130 (2016) 348-355.

[21] R.P. Kambour, A review of crazing and fracture in thermoplastics, J. Polym. Sci. Macromol. Rev. 7 (1) (1973) 1-154.

[22] W.D. Cook, A.E. Mayr, G.H. Edward, Yielding behaviour in model epoxy thermosets-II. Temperature dependence, Polymer 39 (16) (1998) 3725-3733.

[23] P.Y. Le Gac, M. Arhant, M. Le Gall, P. Davies, Yield stress changes induced by water in polyamide 6: characterization and modeling, Polym. Degrad. Stabil. 137 (2017) 272-280.

[24] J. Wise, K.T. Gillen, R.L. Clough, Quantitative model for the time development of diffusion-limited oxidation profiles, Polymer 38 (8) (1997) 1929-1944.

[25] M. Celina, J. Wise, D.K. Ottesen, K.T. Gillen, R.L. Clough, Correlation of chemica and mechanical property changes during oxidative degradation of neoprene, Polym. Degrad. Stabil. 68 (2) (2000) 171-184.

[26] L.M. Rincon-Rubio, X. Colin, L. Audouin, J. Verdu, A theoretical model for the diffusion-limited thermal oxidation of elastomers at medium temperatures, Rubber Chemist. Technol. 76 (2) (2003) 460-482.

[27] K.T. Gillen, M. Celina, R.L. Clough, J. Wise, Extrapolation of accelerated aging data-Arrhenius or erroneous? Trends Polym. Sci. 8 (5) (1997) 250-257. 